\title{
Predicting the Post-Thrombotic Syndrome: Not Quite Ready for Prime Time
}

\author{
Geoffrey D. Barnes ${ }^{1}$ \\ ${ }^{1}$ Department of Internal Medicine, Frankel Cardiovascular Center, \\ University of Michigan, Ann Arbor, Michigan, United States \\ Thromb Haemost 2018;118:1345-1346.
}

Venous thromboembolism remains a major challenge in clinical practice, despite recent advances over the years. ${ }^{1}$ In particular, the post-thrombotic syndrome (PTS) occurs in up to $50 \%$ of patients following an acute deep vein thrombosis (DVT). ${ }^{2}$ Although frequently under-appreciated by many non-specialty providers, this condition is associated with poor quality of life measures and significant societal costs. Yet, predicting which patients will suffer these outcomes has not been an easy task.

In this issue of Thrombosis and Haemostasis, Méan et al publish their risk prediction model for the development of PTS in elderly patients with acute DVT. ${ }^{3}$ They used a prospective multi-centre cohort study of Swiss patients aged $\geq 65$ years with a first acute, symptomatic DVT. Of the 267 patients in their cohort, 161 (58.3\%) developed PTS within the first 24 months of follow-up. As shown in - Table 1, key predictors

Table 1 Risk prediction models for post-thrombotic syndrome

\begin{tabular}{|l|l|l|l|}
\hline & $\begin{array}{l}\text { Méan et al } \\
\text { model }\end{array}$ & SOXtrial model & \\
\hline Age $\geq 75 \mathrm{y}$ & +1 & $\begin{array}{l}\text { lliac vein } \\
\text { involvement }\end{array}$ & 1 \\
\hline $\begin{array}{l}\text { Concomitant } \\
\text { anti-platelet } \\
\text { or NSAID therapy }\end{array}$ & +1 & BMI $\geq 35$ & 2 \\
\hline $\begin{array}{l}\text { Multi-level } \\
\text { thrombosis }\end{array}$ & +1 & $\begin{array}{l}\text { Baseline Villalta } \\
\text { score }>14 \\
\text { (severe PTS) }\end{array}$ & 2 \\
\hline $\begin{array}{l}\text { Prior varicose } \\
\text { vein surgery }\end{array}$ & +1 & $\begin{array}{l}\text { Baseline Villalta } \\
\text { score 10-14 } \\
\text { (moderate PTS) }\end{array}$ & 1 \\
\hline $\begin{array}{l}\text { Other leg signs and } \\
\text { symptoms of PTS }\end{array}$ & $\begin{array}{l}+1 \text { for } \\
\text { each }\end{array}$ & & \\
\hline
\end{tabular}

Abbreviations: BMI, body mass index; NSAID, non-steroidal anti-inflammatory drug; PTS, post-thrombotic syndrome.

Address for correspondence Geoffrey D. Barnes, MD, MSc, Department of Internal Medicine, Frankel Cardiovascular Center, University of Michigan, 2800 Plymouth Rd Building 14 - G101, Ann Arbor, MI 48109-2800, United States (e-mail: gbarnes@umich.edu).

of PTS in this study include frequently cited risk factors (e.g. age, extent of DVT and venous insufficiency) and other easily obtained clinical elements (e.g. medication use and specific symptoms). In their study cohort, $16.3 \%$ of patients were classified as low risk (score, $0-3$ ), of whom $24.4 \%$ developed PTS. More than half of patients (52.5\%) were classified as high risk (score, $\geq 6$ ), of whom $80.7 \%$ developed PTS during the 24-month follow-up period. Overall, the Méan et al risk model had a high discriminatory ability (area under the curve of 0.87 ) with sensitivity and specificity values greater than $70 \%$.

While the data may initially look overwhelmingly convincing, some nuances must be considered. First, this risk model was developed on a modest size population of largely homogenous patients and should be externally validated in more diverse populations before widespread use. This is particularly true given that this score was developed on elderly patients (age $\geq 65$ years) from a single country and therefore may not be generalizable to younger patients and those from other regions of the world or non-Caucasian races. Second, the use of the Villalta scale to define PTS likely impacted the high rates of PTS seen in the study. ${ }^{4}$ PTS defined by Villalta is known to be as many as five times higher than the definitions based on other criteria, such as the Ginsberg criteria, which has been used in more recent studies, such as the SoXtrial. ${ }^{2}$ Finally, while risk stratification can be achieved, how it will impact care remains to be identified. In the case of the Méan et al risk model, the only potentially modifiable risk factor is the concomitant use of anti-platelet or non-steroidal anti-inflammatory drug therapy. Also, it is more likely that the underlying reason that a patient takes these medications is the true risk factor for PTS rather than the use of the medications themselves. Furthermore, the two most promising preventative strategies (use of compression stockings and pharmacomechanical thrombolysis) have not demonstrated benefit in recent trials. ${ }^{5,6}$

(c) 2018 Georg Thieme Verlag KG Stuttgart · New York
DOI https://doi.org/ $10.1055 / \mathrm{s}-0038-1667034$. ISSN 0340-6245. received

June 14, 2018

accepted

June 14, 2018 
Nonetheless, these data are promising and intriguing. First, while the derivation population was relatively modest in size and non-homogenous, the model demonstrated excellent discriminatory ability and reasonably high sensitivity and specificity characteristics, in contrast to the recently developed SOXtrial model ( - Table $\mathbf{1}$ ), which was developed from a larger study cohort but did not have as high a degree of discrimination (c statistic 0.65 vs. 0.79 for the Méan et al model, each in their derivation cohort). ${ }^{7}$ To help put this into perspective, the commonly used $\mathrm{CHA}_{2} \mathrm{DS}_{2}$-VASc stroke risk score for patient with atrial fibrillation had a relatively modest $c$ statistic of 0.61 in its derivation study and 0.66 in a large validation study. ${ }^{8,9}$

Second, while the recent Acute Venous Thrombosis: Thrombus Removal With Adjunctive Catheter-Directed Thrombolysis (ATTRACT) trial of pharmacomechanical thrombolysis failed to show robust benefit for the prevention of PTS in acute DVT patients, there is also reason to think that better patient selection may be associated with benefit. ${ }^{6}$ In that study, only $57 \%$ of the study population experienced proximal DVT and there was a reduction in moderate-to-severe PTS (18\% vs.24\%, risk ratio, $0.73,95 \%$ confidence interval, $0.54-0.98)$. When considered in light of the Méan et al risk model, patients with multi-level thrombosis, prior varicose vein surgery or multiple signs and symptoms of PTS at the time of DVT diagnosis are at increased risk of developing PTS. Perhaps, if these higher risk patients constituted the majority of the ATTRACT trial population then the overall results may have more closely mirrored those of the moderate-to-severe PTS sub-population. This is consistent with the findings of a recent multi-disciplinary consensus panel who recommend future trials of endovascular therapy focus on patients with more advanced forms of PTS and in patients with iliac DVT. ${ }^{10}$

Moving forward, Méan et al have provided interesting data for both clinicians and researchers to ponder. Clinicians may find this tool to be a useful guide when talking to patients about the risk of developing PTS following an acute DVT. However, clinicians should be cautioned about quoting exact point estimates until the risk score is externally validated in broader populations of acute DVT patients. For researchers, it will become important to understand the differences between the Méan et al and SOXtrial models, their respective predictive abilities in diverse populations and how they could potentially impact clinical decision making. ${ }^{3,7}$ It will also be important to understand how well these risk prediction models perform when patient-reported symptoms are used systematically to diagnose PTS. ${ }^{11}$ Indeed, patient-reported outcome measures in PTS have been highlighted, whereby patients with PTS report significantly worse physical health, mental health and disease-specific quality of life. ${ }^{12}$

For a disease as prevalent and debilitating as PTS, any effort to better identify risk and inform therapies designed to prevent its development is a worthwhile endeavour.
Funding

Grant funding from the National Heart, Lung, and Blood Institute, and Pfizer/Bristol-Myers-Squib Consulting for Portola, Pfizer/Bristol-Myers-Squib and Janssen.

\section{Conflict of Interest}

None.

\section{References}

1 Schulman S, Ageno W, Konstantinides SV. Venous thromboembolism: past, present and future. Thromb Haemost 2017;117(07): 1219-1229

2 Wik HS, Ghanima W, Sandset PM, Kahn SR. Scoring systems for postthrombotic syndrome. Semin Thromb Hemost 2017;43(05): 500-504

3 Méan M, Limacher A, Alatri A, Aujesky D, Mazzolai L. Derivation and validation of a prediction model for risk stratification of postthrombotic syndrome in elderly patients with deep vein thrombosis. Thromb Haemost 2017;117(08):1419-1427

4 Villalta S, Bagatella P, Picolli A, et al. Assessment of validity and reproducibility of a clinical scale for the post thrombotic syndrome. Haemostasis 1994;1994(24):158a

5 Kahn SR, Shapiro S, Wells PS, et al; SOX trial investigators. Compression stockings to prevent post-thrombotic syndrome: a randomised placebo-controlled trial. Lancet 2014;383 (9920):880-888

6 Vedantham S, Goldhaber SZ, Julian JA, et al; ATTRACT Trial Investigators. Pharmacomechanical catheter-directed thrombolysis for deep-vein thrombosis. N Engl J Med 2017;377(23): 2240-2252

7 Rabinovich A, Ducruet T, Kahn SR; SOX Trial investigators. Development of a clinical prediction model for the postthrombotic syndrome in a prospective cohort of patients with proximal deep vein thrombosis. J Thromb Haemost 2018;16(02): 262-270

8 Lip GY, Nieuwlaat R, Pisters R, Lane DA, Crijns HJ. Refining clinical risk stratification for predicting stroke and thromboembolism in atrial fibrillation using a novel risk factor-based approach: the euro heart survey on atrial fibrillation. Chest 2010;137(02): 263-272

9 Larsen TB, Lip GY, Skjøth F, Due KM, Overvad K, Hvilsted Rasmussen L. Added predictive ability of the CHA2DS2VASc risk score for stroke and death in patients with atrial fibrillation: the prospective Danish Diet, Cancer, and Health cohort study. Circ Cardiovasc Qual Outcomes 2012;5(03):335-342

10 Vedantham S, Kahn SR, Goldhaber SZ, et al. Endovascular therapy for advanced post-thrombotic syndrome: proceedings from a multidisciplinary consensus panel. Vasc Med 2016;21 (04):400-407

11 Utne KK, Ghanima W, Foyn S, Kahn S, Sandset PM, Wik HS. Development and validation of a tool for patient reporting of symptoms and signs of the post-thrombotic syndrome. Thromb Haemost 2016;115(02):361-367

12 Lubberts B, Paulino Pereira NR, Kabrhel C, Kuter DJ, DiGiovanni CW. What is the effect of venous thromboembolism and related complications on patient reported health-related quality of life? A meta-analysis. Thromb Haemost 2016;116(03): 417-431 